This is a pre-print of an article published in the Journal of Happiness Studies. The final authenticated version is available online at: https://doi.org/10.1007/s10902-020-00234-8

\title{
Asymmetric Social Comparison and Life Satisfaction in Social Networks
}

\author{
Francisco Olivos* \\ The Chinese University of Hong Kong \\ Orcid 0000-0001-6395-6593 \\ Pablo Olivos-Jara \\ Universidad de Castilla-La Mancha \\ Orcid 0000-0001-6259-4658 \\ Magdalena Browne \\ Universidad Adolfo Ibáñez
}

*Corresponding author. Email: fjolivos@ link.cuhk.edu.hk. Tel: (852) 39436625. The corresponding author will share all data and codes for replication purpose upon request.

\section{Acknowledgments}

Thank you to Minhui Liu, Alexis Sossa, Chen Chen, Marcelo Marzouka, and the five anonymous reviewers whose feedback strengthened this article immensely. Francisco Olivos disclosed receipt of the following financial support: Hong Kong PhD Fellowship Scheme and Centre for Social Conflict and Cohesion - COES (Fondap Project Number 15130009). 


\title{
Asymmetric Social Comparison and Life Satisfaction in Social Networks
}

\begin{abstract}
The aim of this study is to understand the effect of asymmetric social comparison on subjective well-being, and how it differs due to reciprocity. Our approach considers the social network of individuals as a local reference group. We tested competing hypotheses on negative and positive effects of comparison with worse-off (downward) and better-off (upward) targets with a representative sample of 1,596 Chileans over the age of 18. The findings support that life satisfaction is influenced by social comparison. By considering the social network as a reference group, the positive effect of downward comparison and the negative effect of upward comparison are confirmed. Upward comparison seems to be more substantial than downward comparison. Additionally, the positive effect of downward comparison decreases slightly with a reciprocal exchange of support between respondents and targets. The application of social network analysis opens a path to understanding the mechanisms underlying social comparison processes.
\end{abstract}

\section{Key words}

Happiness; reciprocity; social networks; asymmetric social comparison.

\section{Introduction}

The social comparison process is considered one of the explanatory mechanisms underpinning individual subjective well-being (Ateca-Amestoy, Aguilar, and Moro-Egido, 2014; Bárcena-Martín, CortésAguilar, and Moro-Egido, 2017; Diener and Fujita, 1997). In this approach, satisfaction with life (SWL) is based on the comparison between one's own characteristics and the characteristics of others better or worse-off (e.g. Carrieri, 2012). However, we know relatively little about social comparison effects derived from others with whom subjects are connected (social networks). Despite these networks being environments that have a great influence on individuals. This research takes into consideration the social network of close acquaintances reported by participants ${ }^{1}$ as a clearly defined reference group (comparison targets), instead of an abstract and exogenous category.

\footnotetext{
${ }^{1}$ The literature in social networks refers to respondents as egos and targets as alters. For the sake of simplicity, we use a general terminology commonly used in social comparison research.
} 
This study has a threefold aim. First, to estimate the effect that comparison with relevant acquaintances, as identified by each subject, has on the own life satisfaction. Second, to understand how these comparisons work in relation to better or worse-off reference groups (upward and downward comparison, respectively). And third, to examine the influence that reciprocity with those relevant others has on this social comparison. By reciprocity, we understand the mutual exchange of support between the individual and their comparison targets, who are members of their social network. This threefold aim enables us to discuss the theoretical equivalence between the definitions of reference groups for social comparisons. Happiness research has used a wide variety of reference groups, such as classmates (Dijkstra, Kuyper, van der Werf, Buunk and van der Zee, 2008), colleagues (Gätcher, Nosenzo and Sefton, 2012; Gätcher and Thöni, 2010), and proximity of residence in the same city (Götz, Ehret, Jullien and Hall, 2006). However, research on the local dominance effect has shown the preeminence of closer targets in social comparison processes when multiple resources are available (Zell and Alicke, 2010). Despite this wide range of groups, social networks have not so far been considered. To our knowledge, this the first study considering social networks as the reference group of comparison. As we shall see later, the social network is the closest social surrounding of each individual and eventually, a more accessible, concrete, and suitable cognitive reference of comparison.

Moreover, this study attempts to understand the cognitive basis of the social comparison process. Previous studies (Ateca-Amestoy et al., 2014; Senik, 2008; McBride, 2001) have been grounded in the analysis of the material life circumstances of a reference group, mainly income. Discussions on income reference groups are a growing field of research with a broad perspective. Senik (2008) and McBride (2001) showed that individual subjective well-being depends to a large extent on the income of the reference group. However, since the emergence of social psychology and the study of social influence, social comparison has been considered to encompass individual perception, social cognition, and motivation, in which a subject processes information about specific other individuals. Consequently, the study of social comparison may consider individuals' perceptions about their life circumstances and their perceptions of those of comparison targets (Fiske, 2010). The present research attempts to go one step further by explaining the association between these two cognitive judgments made by an individual. Therefore, the domain of comparison is the happiness of the participants and the happiness of his/her acquaintances as perceived by this individual. Following current theoretical developments in happiness studies (Diener, Lucas and Oishi, 2018), we regard happiness as a global subjective 
evaluation. Thus, we study the effect of individuals' comparison of this overall evaluation on its cognitive component: respondents' SWL. However, we refer to both indistinctly since they can be considered as part of the "trait happiness" (Raila et al., 2015).

Finally, an additional contribution is the focus on the case of Chile. Studies of the relations between social comparison and life satisfaction in this country are of interest as the empirical research on this subject has mainly been conducted in developed countries (e.g. Rodríguez-Pose and von Berlepsch, 2014). In contrast to studies in developed societies, the evidence has shown that nations with comparatively high averages of happiness are linked to lower per capita GDP (Beytía, 2016). This paradox is explained by the importance of social capital (Ateca-Amestoy et al., 2014). Several Latin American countries rank in the highest positions in different indexes aimed to measure well-being across populations. Any country in the region could be a compelling case of study.

We focused on Chile because, in the last years, it has been consistently ranked among the happiest countries in the region by the United Nations (Helliwell et al., 2017). Paradoxically, at the same time, Chile is among the most unequal countries in the world, making it an adjudicative case (Torche, 2005). Moreover, the case of Chile is interesting because it assembles similarities and differences with the remaining Latin American countries. It is a prototypical case with the main characteristics of Latin American nations: a developing country, Spanish speakers, a majority Roman Catholic population, a contemporary history linked to a long period of a military government, and a neoliberal political economy. Nevertheless, there are certain characteristics that make Chile a unique case study. In the last three decades, Chile has undergone unprecedented changes: reduction of poverty, increased GDP, and longer life expectancy (The World Bank, 2017), which are all important determinants of life satisfaction (Beytía, 2016; Moyano-Díaz, 2016). According to Rojas (2016), if an income-based criterion for defining development is used, Chile has shown the best performance in the Latin America over the last two decades.

Our analysis is performed using the Happiness Barometer (Barómetro de la Felicidad) (Dirección de Estudios Sociales Universidad Católica, 2015), which was conducted in 2015 with a probabilistic sample of Chilean participants. It enables us to generalize our conclusions to an entire country population. The survey is unique in simultaneously providing measures of the subjective well-being of individuals and close 
acquaintances by means of a name generator, which is a procedure that lets respondents give a list of comparison targets with whom they share strong ties.

This article is structured in four sections. First, we derived a theoretical model from an asymmetric social comparison framework developed summarized in Figure 1. Second, participants, measurements and analytical strategy are described in the method section. Third, hypotheses testing is reported in the results section. And fourth, findings are discussed in the conclusion section.

\section{Social Comparison}

Since the pioneering article published by Festinger (1954), the comparison process has been considered a fundamental aspect of the human condition (Jasso, 1990). As Wood (1996) explains, social comparison is a "process of thinking about information about one or more other people in relation to the self" (1996:520-521). Three major processes are involved in social comparison (Wood, 1996). First, acquiring social information (e.g. directly examining, reading about others, hearing about another person). Second, thinking about the acquired social information in relation to the self. And third, reacting to the comparison. Thus, through these processes, humans compare themselves with others, and judgments and feelings such as life satisfaction emerge as reactions from these comparisons. As we will discuss later, the information could be about better- or worse-off others.

Nonetheless, this approach has been the subject of much debate. Today we know that people compare with similar targets, but also with different others by contrastive comparison (Mussweiler, Rüter and Epstude, 2004). Moreover, the social comparison could be an implicit (automatic) or explicit (controlled) process (Gilbert, Giesler and Morris, 1995). In happiness research, social comparison theory has generated a large body of literature suggesting that the influence of social comparisons on life satisfaction may reside in the existence of envy and signal effects (Ateca-Amestoy et al., 2014). Thus, in the process of comparison, people's good news could be bad news for the self or prognosis of subject's future. The former refers to envy effects, while the latter to signal effects. We focus on the comparison between individuals' and reference group's happiness since it is a general subjective evaluation and more accessible information than life satisfaction. Since life satisfaction is the cognitive component of happiness (Diener, Lucas and Oishi, 2018; Raila et al., 2015), it is more difficult for individuals to make judgments about the degree to which the conditions of others' life are ideal. 


\section{Definition of comparison targets.}

In order to define our hypotheses, certain elements of social comparison theory should be highlighted. First, identifying the group of reference for individuals' judgments is one of the difficulties of research in social comparison. Many studies have chosen to define a group exogenously (e.g. Ateca-Amestoy et al., 2014). Based on the principle that comparison is made by considering similar others (Festinger, 1954), research imposes a comparable reference group. Studies vary, focusing on countries, inhabitants of the same region, individuals from a specific age rang,e or a combination of socio-demographic characteristics shared by individuals and the group. Despite being similar to the individual, the disadvantage of imposing a reference group is that of considering a group that is not relevant for comparison.

A small number of studies consider group endogenously defined by subjects. In this way, for example, Young, Gabriel, and Schlager (2014), studying appearance-related comparison within women's close friendships, asked participants to provide the names and traits of close female friends and remember details of recent time spent with them in order to control for bias. Considering the nearest social network as a reference group overcomes the drawbacks of imposing one.

A large body of literature considers the social network as an essential reference group (e.g. Marsden and Friedkin, 1993). In the study by Fisher (1988), people adapt their behavioral norms according to their social comparison with social networks. The social network exerts an informational influence on individuals. The normative and informational influence will promote or inhibit the individual's risk behaviors. Perceptions about the rate of negative events in a social network affect actors' feeling of vulnerability. This approach considers that the targets who make up the social network are the individual's closest social surroundings and the most accesible opportunity for comparison. Therefore, social networks are more concrete and suitable reference groups. In addition, the only condition for the social influence of a reference group is information, which allows social comparison (Marsden and Friedkin, 1993). However, a social network of significant others includes stronger relationships than solely informational ones. Closer ties are characterized by greater emotional intensity, reciprocity, intimacy, and amount of time (Granovetter, 1973). Therefore, the effect of downward and upward comparison might vary if an abstract group or the social network are considered as reference groups.

In addition, the literature in the local dominance effect also highlights the relevance of social networks for social comparison. As Zell and Alicke (2010) have shown, when individuals have multiple resources of 
information, ranging from particular persons to generalized targets, local comparison dominates and supersedes the effect of general comparison. Henceforth, close acquaintances are relevant to subject's happiness. A broad literature testing "frog-pond effect" in academic contexts indicates that perception of academic competence is affected by peers (Marsh and Hau, 2003), who are located in a close surrounding. In happiness studies, the evidence by Firebaugh and Schroeder (2009) suggests that happiness is affected by the income of those "living nearby": Americans tend to be happy when they live among rich neighbors. However, they are happier living with the poor, only when they live at a distance (e.g. in another neighborhood within the same city). Therefore, as discussed in the following subsection, it indicates that not only local dominance may be considered, but also processes of asymmetrical comparison.

\section{Asymmetric social comparison.}

Secondly, among the further refinements of social comparison theory, the distinction between upward and downward comparisons, as an asymmetric process, has been one of the more influential conceptualizations in the field of happiness research. For instance, Wills (1981) stated that persons experiencing harsh life circumstances can enhance their subjective well-being by means of comparison with less fortunate others. In a further development, Taylor and Lobel (1989) showed that comparisons with less fortunate others (downward comparison) and with more fortunate others (upward comparison) exist simultaneously in the same person under the same conditions. According to these authors, there are different kinds of comparison activities with divergent empirical patterns and responses to diverse needs.

For downward comparison, there are two different plausible mechanisms for explaining the effect on life satisfaction. First, downward comparison could be motivated by solidarity. From this perspective, downward comparisons would be altruistically oriented. Schlosser and Levy (2016) conducted four randomized experiments, finding that beliefs of "being a better person" and "giving back" mediate the propensity to give when the comparison is with a downward group. These findings are robust, emerging across student and nonstudent populations, and different domains of comparison. People with this motivation are less focused on selfimprovement due to a sense of superiority (Taylor, Wayment, and Carrillo, 1996) or the facilitation of selfenhancement (Corcoran, Crusius, and Mussweiler, 2011): looking at the situation of disadvantaged individuals would produce unhappiness, sadness and powerlessness, because subjects are aware of their advantage and because this status could decline due to similarity with less fortunate others. In a study with cancer patients, 
Buunk and colleagues (1990) found comparing with a downward target produced a more likely negative reaction. Patients' self-esteem and the perceived control of their illness decline when they compare downwards. The same study reveals similar findings for married people and marital disaffection.

However, a second explanation is possible. Downward comparison is a signal of a person's possible state, which leads to a positive evaluation of the present state. For instance, if the reference group is dissatisfied, the person who is comparing will be happy not to be in that state (gratitude). Individuals may be happy to not be in that position, even though there are signals that he/she should be in the target's position. Wills (1981) explains that persons affected by situations of misfortune or frustration, which are unsolvable by means of instrumental action, will seek to restore life satisfaction by social comparison. In these cases, the reference group would be a worse-off group. The comparison between oneself and less fortunate others enables an individual to feel better about their life circumstances by feeling grateful not to be in their position. Tajfel (1982) suggests that by comparing with less fortunate others, persons build up a positive self-image. In another study, Buunk and Ybema (2003) show that comparison with women with a lower level of marital quality will enhance happiness and increase satisfaction with one's own circumstances: they feel bad for the others but satisfied with themselves. Thus, competing hypotheses are derived:

\section{Hypothesis 1A: The larger the happiness gap between an individual and their less fortunate} reference group, the lower is the SWL.

Hypothesis 1B: The larger the happiness gap between an individual and their less fortunate reference group, the higher is the SWL.

Likewise, empirical research has also addressed upward comparison, finding both a negative and positive effect on life satisfaction. Similarly, upward judgment may be driven by two different mechanisms. First, the individual may feel envious of the reference group: a desire to have what the others have. Hence, when people compare themselves with a more fortunate reference group, they will feel more dissatisfied with their circumstances (Diener and Fujita, 1997). Fiske (2010) explains that feeling below somebody else makes people feel ashamed of their own situation. If comparison targets succeed, then the individual feels inadequate for not performing equally well or angry because of the unfair advantages and the injustice of their position. For instance, Frison and Eggermont (2016) studied the interaction of adolescents on Facebook. Their findings also showed a decrease in life satisfaction over time because of negative upward comparison. 
As far as the second argument is concerned, the positive effect of comparing with more fortunate others is explained by the signaling theory. Persons make judgments about their life circumstances based on understanding the situation of others as their own possible state in the future. This is because they believe they have positive characteristics. Thus, self-views are enhanced by means of awareness of similarity with the upward target. As a result of identifying with the reference group, individuals may see the other's fate as their own actual or possible fate (Frieswijk, Buunk, Steverink, and Slaets, 2004). Subjects recognize themselves in others: "That they are among the better ones" (Collins, 2000:170). Therefore, upward comparison evokes positive feelings because of a sort of affective contagion process (Hatfield, Cacioppo, and Rapson, 1994), where the good fortune of the reference group is adopted in part by egos. For instance, Boissicat and colleagues (2012) found that upward comparison enhances the self-perception of the scholastic competence of fourth and fifth grade students. The authors argue that the signaling effect of upward comparison is more common in educational settings. But upward signaling effects have also been found in other fields, such as the labor market (Welsch and Kühling, 2015) and marketing (Feiereisen, Broderick and Douglas, 2009). Based on this literature, the following competing hypotheses are derived:

Hypothesis 2A: The larger the happiness gap between an individual and their more fortunate reference group, the lower is the $S W L$.

Hypothesis 2B: The larger the happiness gap between an individual and their more fortunate reference group, the higher is the SWL.

The prevalence of one kind of asymmetric comparison over another is a matter of discussion and empirical testing. Duesenberry (1949) initially proposed the idea that most comparisons are upwards, where poorer individuals compare themselves with more affluent people. The empirical evidence presented by Ferreri-Carbonell (2005) supports the prevalence of this upward comparison. In line with Ferrer-i-Carbonell (2005), for a sample of Latin American countries, Ateca-Amestoy et al. (2014) found an effect of upward comparison on life satisfaction, where relative wealth is only relevant for individuals below the average income in the reference group. In other words, they found no evidence supporting downward comparison for Latin American countries. However, the results could be explained because the study uses exogenously created reference groups. From a social network approach, social comparison rooted in close individuals would have more information for making judgments than that based on an exogenous reference group. Taking into account that 
closer acquaintances have more influence on individuals than distant persons, downward comparison should affect their satisfaction if the social network is considered as the reference group. Nonetheless, based on the existing evidence, the effect of upward comparison is expected to be larger than that of the downward comparison:

Hypothesis 3: The effect of downward comparison on SWL is expected to be smaller than that of upward comparison.

\section{Reciprocity.}

The social influence on subjective well-being has traditionally been a central debate in happiness research. However, there is a lack of empirical research on the moderation of the structural characteristics of the social environment. If the social comparison process takes place in a social network, the characteristics of this social network would be addressed. Relationships between individuals and their comparison targets within the social network are heterogeneous. Thus, the effect of social comparison should vary depending on the characteristics of those ties.

Since the earliest developments of social comparison theory, the approach has been criticized for the omission of many important components, such as the cohesiveness of groups (Singer, 1980). Group cohesion has long been considered one of the most relevant structural characteristics in the explanation of the social influence process (Back, 1951; Festinger, 1954). Considering the heterogeneity of ties, social comparison analysis is a more realistic approach. Reciprocity is one of the straightforward dimensions of cohesiveness (Granovetter, 1973) and one of the strongest social forces in all societies. Reciprocation refers to the norm of paying back what we have been given (Emerson, 1976). The general hypotheses tested by social network and social exchange analysts is that reciprocity among actors in networks is related to more influential interpersonal relationships (Cook and Rice, 2006; Marsden and Friedkin, 1993).

According to Contractor and DeChurch (2014), reciprocity is a type of social interaction, which explains how the behavior of one person depends upon the attitude and behaviors of others in their social environment. The reciprocity in others-based processes, such as social comparison, gives rise to a need for interpersonal attachments (Baumeister and Leary, 1995). Therefore, the social influence in a reciprocal social exchange is driven by a social motive of belonging, forming meaningful social relationships, or simply connecting with others (Cook and Rice, 2006). Characteristics, attitudes, and behaviors of reciprocal others will 
have a stronger influence on the evaluation of one's own circumstances. The following moderating hypothesis is derived:

Hypothesis 4: As the reciprocity increases, the association between downward/upward comparison and SWL increases.

In sum, the competing hypotheses on the effect of asymmetric social comparison on life satisfaction will be tested in the following section ( $\mathrm{H} 1 \mathrm{~A}$ to $\mathrm{H} 3)$, as well as the role played by reciprocity between individuals and targets in fostering this relationship (H4). A simplified representation of the hypotheses is shown in Figure 1. Thus, by studying the case of Chile, this theoretical model attempts to contribute to the development of social comparison theory. Specifically, we examine the theoretical equivalence of social networks as a target group with other reference groups previously studied. Since social networks are the closest social surrounding of individuals, we unfold the social comparison process for a more accessible, concrete, and suitable cognitive reference of comparison.

[Figure 1]

\section{Method}

\section{Participants.}

To pursue the analysis of the relationships proposed in the hypotheses, this study uses data from the 2015 edition of the Happiness Barometer (Dirección de Estudios Sociales Universidad Católica, 2015), a survey on happiness issues, which includes answers to social network-related questions. This combination of measures makes this dataset a unique resource for testing these hypotheses.

The sample comprises 2,267 Chileans over the age of 18 who were interviewed face-to-face between November 2014 and January 2015, with a break during Christmas and New Year. Regarding the sampling of interviewees, the probabilistic sample was based on a multistage stratified design. Firstly, we divided Chile into four zones as strata. Secondly, we randomly selected the following units in a multistage procedure: cities with more than 25,000 inhabitants, blocks, homes and habitual residents of these homes over the age of 18 . The selection of cities and blocks was carried out proportionally to population size. The sampling error for this study is \pm 2.1 , on the assumption of simple random sampling, maximum variance, and a confidence level of $95 \%$. In order to test our hypotheses, the original sample was doubly restricted. Firstly, to disentangle the comparison 
based on social networks, only respondents with at least one target listed were considered in the analysis $(\mathrm{N}=$ 2,127). Secondly, a listwise deletion ${ }^{2}$ was applied for handling missing data and defining a comparable analytic sample across models. As a result, the sample was further restricted to 1,596 of 2,267 respondents who completed the questionnaire.

\section{Measurements.}

\section{Dependent variable.}

Satisfaction with Life Scale. The Barometer of Happiness uses different measures of life satisfaction, including satisfaction with health, friendship, family and work. For this study, the dependent variable is the score on the Satisfaction with Life Scale (SWLS), which is the sum of 5 items. It is a single factor measuring global cognitive judgments about satisfaction with one's life (Diener, Emmons, Larsen, and Griffin, 1985). The respondents rated their degree of agreement with each statement using a 7-level Likert scale ranging from 1 “completely disagree" to 7 "completely agree." Item scores are summed into an overall score, ranging from 5

to 35. Since its introduction, the SWLS has been widely used to assess the life satisfaction component of subjective well-being due to its good psychometric characteristics (Pavot and Diener, 1993, 2008). For the Chilean population, studies have reported adequate levels of internal consistency and construct validation (Vera-Villarroel et al, 2012; Moyano-Díaz, 2010). In this study, the SWLS shows a high level of internal consistency (Cronbach's $\alpha$ of 0.90) and the average score is 23.97 units. Descriptive statistics and wording of each variable of the scale are presented in Table S2 in Supplementary material II. Due to the low proportion of cases in the extreme values, ceiling, or floor effects are dismissed.

\section{Independent variables.}

Downward and Upward comparison. Comparison variables were measured using a name generator, where participants were asked to name up to five persons (called comparison targets) they had spoken to most during the previous six months (relatives included). The name generator is an ego-network elicitation method, where respondents are limited to describing a fixed number of acquaintances (comparison targets in this study).

\footnotetext{
${ }^{2}$ Listwise deletion is a common practice for handling missing data in happiness studies (e.g. Cohen, 2002; Steele and Lynch, 2013; Yang, 2008). It is recommended when incomplete information is missing at random (Allison, 2000). As we can see in Table S1 in Supplementary material I, no serious problems of missing data were detected, and the main statistics did not change substantively after this listwise deletion. Therefore, we could assume randomness.
} 
Therefore, analyses are restricted up to five relevant others ${ }^{3}$. They were asked nine questions about the comparison targets, including age, education, and gender ${ }^{4}$.

For each target listed, respondents were asked “Overall, how happy do you think [name] is?”. Answers range from 1 (very happy) to 4 (nothing happy). Values were reversed for a logical interpretation. Targets' reference happiness is the average happiness reported by the respondent for up to five targets listed. The mean comparison approach has been widely used in the existing evidence. This approach considers changes in the reference group resources to affect individual-level satisfaction in a similar way across the board (AtecaAmestoy et al., 2014; Bárcena-Martín et al., 2017; Ferrer-i-Carbonell, 2005). Each respondent answered the same question regarding themselves. Both the mean happiness of the network and individuals' happiness were used to create the comparison variables as follows.

We draw on an operationalization widely used in social comparison research (Ateca-Amestoy et al., 2014; Bárcena-Martín et al., 2017; Ferrer-i-Carbonell, 2005). An asymmetric conceptualization of the comparison effect is considered, where the comparison targets' characteristics influence the participant's life satisfaction differently. We define the variables Down and Up as:

$$
\begin{gathered}
\text { Down }_{i}=\left\{\begin{array}{cc}
\left|y_{i}-\bar{y}_{i r}\right| & \text { if } y_{i} \geq \bar{y}_{i r} \\
0 & \text { if } y_{i}<\bar{y}_{i r}
\end{array}\right. \\
U p_{i}=\left\{\begin{array}{cc}
\left|y_{i}-\bar{y}_{i r}\right| & \text { if } y_{i} \leq \bar{y}_{i r} \\
0 & \text { if } y_{i}>\bar{y}_{i r}
\end{array}\right.
\end{gathered}
$$

where Down represents the downward comparison of participants $i$ who are happier than targets. When the reference group $r$ of individual $i$ has an average happiness $(\bar{y})$ higher than the individual happiness $(y)$, Down takes zero value. In contrast, when an individual $i$ is happier or equally happy than comparison targets, we subtract the average happiness from individual's happiness. Thus, higher is the absolute value, higher is the

\footnotetext{
${ }^{3}$ According to Miller and others (2015), some respondents may fill out name generators with just a few strong ties while others with mere acquaintances. Thus, the definition of up to five targets ensures a standardized set of "close ties" across respondents. Indeed, a limit of three targets is a common practice in name generator research (Miller et al., 2015). From the fully restricted sample, the most frequent network size is one acquaintance ( 34.6 percent).

${ }^{4}$ Past research has discussed the vulnerability of name generators to "interviewer effect" where characteristics of interviewers could affect responses (e.g. Mardsen, 2003; Eagle and Proeschold-Bell, 2015). For this survey, in the case of the network size, the intraclass correlation (ICC) was 0.28 , which means that 28 percent of the variance in the network size could be attributed to interviewers' characteristics. Similar studies conducted with CAPI mode have found similar or higher ICC. Josten and Trappmann (2016) found an ICC of 0.30 in German panel survey "Labour Market and Social Security" (PASS) and Brüderl, Huyer-May and C. Schmiedeberg (2013) an ICC of up to 0.40 for the second wave of German Socioeconomic Panel. This level of ICC is explained by the difficulty of supervision in applications of CAPI surveys. For the case of the Happiness Barometer, CAPI mode was the only alternative available for conducting a survey of a representative sample of a whole developing country.
} 
distance between individual's happiness and worse-off comparison targets. Upward comparison (Up) of individual $i$ is estimated in the same way but subtracting the average happiness of targets in the case when individuals are less or equally happy. Hence, higher is the absolute value, higher is the distance of the individual with the average happiness of their better-off comparison targets.

Reciprocity. For each comparison target listed in the name generator, the corresponding participant declared his or her willingness to support them: "if [name] would have a problem, how much would you be willing to support them?". Answers range from 1 (very willing) to 4 (unwilling). Furthermore, the respondent also declared whether he or she would receive support from each target: "if you have a problem, could you count on [name] to solve it?". Answers range from 1 (Yes, of course) to 3 (I don't think so). The indicator of reciprocity was constructed as a dichotomous variable where the respondent declares whether they have a complete reciprocal exchange ( 1 in both indicators) of support with each named target or not. The measurement included in the analysis is a binary variable, where 1 represents networks with reciprocity with all the comparison targets listed by respondents and 0 for four or less reciprocal relationships. As mentioned above, it only considers participants with one or more comparison targets.

\section{Controls.}

Even though this study is not aimed at assessing a causal relationship, two groups of control variables were included in the analysis in order to reduce possible bias due to potential confounders. The first group of control variables is formed by sociodemographic predictors of life satisfaction suggested by the literature.

Age is included in the analysis as a continuous predictor. A quadratic term of age is considered to address non-linear effects. Educational level is a binary variable equal to 1 when the respondent completed higher education, and 0 for lower educational levels. Given non-response issues, the educational level has been used as a proxy of socioeconomic status. Following the sorting model (Campbell, 2009; Nie, Junn, and StehlikBarry, 1996), more education implies a higher social status. Gender is assessed by a binary variable labeled 1 for male respondents and 0 for females. Previous empirical research suggests a relationship between these three variables and life satisfaction. An increasing body of literature documents a $U$-shaped relationship between age and life satisfaction (Blanchflower and Oswald, 2008). Moreover, as theory explains, there is an association between life satisfaction and socioeconomic status and because it helps to fulfill basic (for example, shelter, food) and psychological needs (for example, autonomy) (Diener, Oishi and Tay, 2018). Researchers also 
suggest a relationship between gender and indicators of subjective well-being in Latin American samples (e.g. Esnaola et al., 2019).

The control for employment status has been considered by including three binary variables (1 "Yes" and 0 "No"). First, the employment status, which considers whether the respondent has a paid job or is selfemployed. Second, the unemployment status, where the individual is coded as 1 if unemployed. And third, an inactive status variable scoring 1 for individuals who are homemakers, studying, retired, or unable to work. It is essential to control by employment status due to consistent evidence suggesting a causal effect of unemployment on reduced life satisfaction and mental health, including the meta-analysis by Paul and Moser (2009).

Similarly, three categorical variables are defined for measuring marital status. First, the variable single is equal to 1 when the individual has never married. Second, the value of the married status is 1 if the respondent is married or is cohabiting. And third, other status variable scores 1 if the individual is separated, divorced, or widowed. Finally, the self-perception of health is included as a proxy of health status. It ranges from 1 (very bad) to 5 (very good). According to the empirical evidence, both marital (e.g. Park et al., 2019; Bucher et al., 2019) and health (Diener, Oishi and Tay, 2018; Park et al., 2919) statuses are significant predictors of life satisfaction. In particular, divorce, death of a partner and, illnesses are disrupting events that could affect individuals' well-being negatively.

The second group of variables addresses endogeneity biases due to non-sociodemographic factors. First, as discussed above, social networks' composition and volume of social resources are important predictors of life satisfaction (Huang et al., 2019). Therefore, models are controlled by network size and compositional characteristics. Moreover, individuals might select their social network members based on similar tastes, attitudes, and sentiments, which are also likely to be correlated with social comparison processes. The size of the network is included in the model, measured as the number of targets listed in the name generator. For the sake of simplicity, it is included as continuous. Additionally, every respondent provided characteristics of each listed target regarding educational level (1 "higher education" and 0 "less than higher education"), gender (1 "male" and 0 "female), kinship (1 "family member" and 0 "non-family member") and age. Therefore, proportions of comparison targets with higher education, females, kindship, and the average age are included as controls. 
Second, a potential date bias is considered by means of an ordinal variable: 1 for questionnaires surveyed from November 1 st to December 15 th; 2 for questionnaires surveyed from December 16 th to January 1st; and 3 for questionnaires survey from January 2nd to January 30th. Festivity and holiday biases are captured by the second and third categories, respectively. Table 1 reports descriptive statistics of the variables after restrictions of the sample ${ }^{5}$.

[Table 1 here]

\section{Analytic strategy.}

In order to test our hypotheses, and considering the characteristics of our dependent variable, seven Ordinal Linear Squares (OLS) regressions labeled from A to G were estimated. The models are of the form:

$$
Y_{i}=\beta_{0}+\beta_{1} \text { Down }_{i}+\beta_{2} U p_{i}+\beta_{3} \operatorname{Rec}_{i}+\beta_{4} S_{i}^{\prime}+\beta_{5} N_{i}^{\prime}+\mu_{i}
$$

where $Y$ is the observed level of satisfaction with life for individual $i$; Down and $U p$ are the social comparison predictors that may affect individual satisfaction with life; Rec is the reciprocity between individuals and targets; $S^{\prime}$ is a vector of the first group of control variables, including individual characteristics; $N^{\prime}$ is a vector of network characteristics and survey date, and $\mu$ is a normally distributed error term. For the sake of simplicity, interactions between $\operatorname{Rec}$ and social comparison predictors are not included in the formula.

Model A includes only social comparison predictors. Model B incorporates the vector of individual characteristics as control variables. Model C considers the second vector aimed to control for network characteristics and potential date bias. Reciprocity between participants and comparison targets are included in Model D, which is interacted with downward and upward comparison in Models E and F, respectively. Finally, as a robustness check, we estimated a fully interacted model -that is, a regression with both interactions simultaneously and the rest of independent variables. This model evaluates the robustness of the estimated effect under the control of heterogeneity in the data that is explained by our covariates and interactions among them. We conducted all the analyses using Stata 14.

\section{Results}

\footnotetext{
${ }^{5}$ Correlations are reported in Table S3 in the Supplementary material. In general, low levels of correlation are reported. Downward and Upward comparison report a higher level of correlation, which could produce multicollinearity in the regression. However, this bias only could affect standard errors and not coefficients. Indeed, although there is a level of correlation, the coefficients of both variables are still significant. Therefore, it provides robustness to our estimations.
} 
Table 2 shows the effects of asymmetric social comparison on life satisfaction. Both downward and upward comparison explain $6 \%$ of the variance of participants' life satisfaction, which is a substantial proportion. Model A suggests a positive effect of downward comparison $(B=0.673 ; p<.05)$ on respondent's life satisfaction. It indicates that a larger gap between respondents and the worse-off reference group produces an increase in life satisfaction. This result leads us to reject Hypothesis 1A and support Hypothesis 1B. The same model shows a significant and negative effect of the upward comparison $(B=-2.689 ; p<.01)$. The direction of the effect means that an increase in the gap between subjects and a more fortunate reference group results in decreased life satisfaction. Hence, for upward comparison, Hypothesis 2A is supported.

A set of individual-level control variables was included in Model B. Downward and upward comparison remains significant, in the same direction and similar magnitude. Regarding control variables, these results contribute positively to the discussion about the determinants of life satisfaction in Latin American countries. First, the linear $(B=-0.147 ; p<.01)$ and squared $(B=0.162 ; \mathrm{p}<.01)$ effects of age are also statistically significant. These effects are consistent, as suggested by the literature. Second, those married $(B=1.641 ; p<$ $.01)$ or highly educated $(B=1.358 ; p<.01)$ are respectively happier than those who are single or have a low educational level. An increase in self-perception of health has a positive and significant effect on respondents' life satisfaction $(B=1.793 ; p<.01)$. Finally, there are no gender or employment effects on life satisfaction.

Model C includes network characteristics and date of the survey for controlling purposes. Given the endogenous nature of networks, the effects have to be controlled by network characteristics. The network size has a positive effect $(B=0.619, p<.01)$ on the dependent variable, which indicates that the larger a respondent's social network is, the higher is their life satisfaction. A higher proportion of family kinship $(B=1.028 ; p<.01)$ and targets with higher education have a positive effect on SWLS $(B=1.316 ; p<.01)$. Gender and age composition have no effect on the dependent variable. After these controls, the main effect remains significant and in the same direction as previous models. Altogether, these variables explain $18 \%$ of the variance in life satisfaction.

Most existing literature is framed in the mean dependence approach, which considers an exclusion restriction whereby individuals compare themselves only to the average characteristic of the network (AtecaAmestoy et al., 2014; Ferrer-i-Carbonell, 2005). In this work, the sensitivity of the models to the measure of the reference happiness level is assessed. Two additional measures of the reference happiness (not reported here 
for the sake of space) were considered: the median and the mode of the happiness of the network's members. The main effects are confirmed for these models. Furthermore, in order to compare the magnitude of both downward and upward effects, a Wald $F$ test drawn from Model G indicates a significant difference between downward and upward coefficients in statistical terms $(F(1,1577)=86.60$, Prob $>F=0.000)$, which indicates that the envy effect is stronger for participants than the feeling of gratitude. Therefore, Hypothesis 3 regarding a larger effect of upward comparison is supported.

[Table 2 here]

According to Bruchmann (2017), any comparison between downward and upward effects should take into consideration a control group, as the non-controlled comparison between two effects is biased. To overcome this problem, we conducted Propensity Score Matching (Rosenbaum and Rubin, 1983) to create treatment and control groups of highly similar characteristics. This analysis is reported in Supplementary material III. These results are in the same direction as the results in the previous models. By considering a control group for each treatment, the PSM indicates that the effect of upward comparison is larger than the effect of downward comparison as stated above (Table S5, Supplementary material III). PSM provides robust estimation against observed possible confounders. No unobserved confounders are assumed.

Table 3 reports the multivariate OLS models, including the interaction between social comparisons and participant-targets reciprocity. Model D shows a positive effect of reciprocity on participant's life satisfaction $(B=2.368, p<.01)$. In other words, the higher the average reciprocity is with targets, the greater is the increase in satisfaction with one's life circumstances. Model E suggests that a reciprocal relationship between comparison targets and respondents decreases the effect of downward comparison on life satisfaction $(B=-1.554, p<.1)$. In other words, when a participant has a more reciprocal relationship with their worse-off targets, their life satisfaction increases less by downward comparison. However, the interaction is just marginally significant. By contrast, the interaction between reciprocity and upward comparison is not statistically significant in Model F, which suggests that the negative effect of upward comparison is neither reduced nor increased by cohesion between participants and targets. Finally, Model G includes both interactions simultaneously. In this case, the significant interaction between downward and reciprocity is confirmed but is marginally significant. Moreover, the effect of downward comparison $(B=2.570, p<.01)$ is larger than upward comparison $(B=-1.762, p<.01)$ when there is no reciprocity $(F(1,1574)=24.96, p<.01)$. This result 
contradicts Hypothesis 4, where reinforcement of upward and downward comparison was expected due to social influence.

[Table 3 here]

\section{Discussion and Conclusions}

This study aimed to examine how downward and upward comparisons between individuals' and targets' happiness explain life satisfaction, taking into account the influence of social networks on individuals. Our findings support that life satisfaction is influenced by social comparison. By considering the social network as a reference group, and happiness as the resource of comparison, the positive effect of downward comparison (H1B) and the negative effect of upward comparison (H2A) were supported. In addition, the effect of downward comparison is slightly reduced by reciprocity with the reference group (H4). The effect of comparison with more fortunate others is greater than that of comparison with a less fortunate reference group (H3). Therefore, it is possible to assume that the feeling of envy seems to be stronger than that of gratitude. These hypotheses were tested using a unique dataset that combines social network data with life satisfaction measurements for Chile.

The theoretical equivalence of social networks with previously studied reference groups cannot be established. The mechanism underlying the effect of social comparison would have different dynamics if considering social networks instead of aggregated groups. For social comparison, the informational base of influence does not require a close relationship between individuals and members of the reference group. Comparing with an exogenous or abstract reference group, the social network as a reference group involves a closer relationship among actors. Therefore, upward and downward comparisons produce different reactions in the individual than the findings reported in previous studies.

The supported effects of upward and downward comparisons have an element in common. Both are

closer to an individualistically grounded life satisfaction, where comparison might be guided by feelings of envy and scorn, instead of solidarity or empathy. This individualistic social comparison seems to contradict the idea that life satisfaction in Latin America is collectively grounded, at least for the case of Chile. Further studies should directly measure collectivistic and individualistic values to discuss whether these effects are driven by these values. The classic individualistic approach (Hofstede, 1980) considers individualistic societies to be where individuals predominantly view themselves as autonomous, bounded and unitary agents. However, in 
this case, life satisfaction is a construction of an individual's comparing him or herself to a primary reference group but being guided by a self-centered intention. Furthermore, these findings could contribute to a more complex predominant dualistic approach of individualistic-collectivistic societies (Diener, Suh, Smith, and Shao, 1995). Based on the Chilean case, we have a situation where life satisfaction may be rooted in close ties (United Nations Development Programme, 2012) but with social comparison guided by individualistic interest.

However, the limitations of our measurements and data make the conclusions regarding the effect of social comparison on life satisfaction tentative. For instance, there are insufficient measurements to characterize the cohesiveness of social networks in all its dimensions, such as length of relationships or intensity. Although the operationalization of comparison targets from the nearby social network and subjectively signified by the participants themselves is a contribution, it could contain a bias that should be overcome in future studies. Previous evidence (Mussweiler, 2003) has shown a sensitivity to personal evaluation when comparing with the individual characteristics of others, and people generally perceive friends as similar (Morry, 2005). In our study, the five members of the network are considered as equal, to create the target variable, regardless of their differences of age, gender, educational level, or kinship. Estimations were controlled for by network size and composition characteristics, without significant effects. However, it is not exhaustive, and other unobservable characteristics remain empirically untested. Additionally, our conclusion can be generalized only to the closest social environment. There is an effect of the broader social network or weaker ties that cannot be examined.

The application of social network analysis opens a path to understanding the mechanism underlying the social comparison process. One way to further examine the role of social networks in the social comparison process is to investigate the effect of different structural characteristics and full networks (more than five targets). Our findings suggest that reciprocity diminishes the effects of social comparison, although the social networks may vary in aspects such as length of relationship and density. These characteristics may moderate how comparison targets influence individuals. All of them are alternatives to be tested in future studies.

In addition, the analysis has examined the influence of the closest targets, but the network may be extended, and the influence of comparison targets might go beyond this nearest circle of acquaintances. Our results suggest the need for further empirical investigation of other sources of comparison. For example, Van Praag, Frijters and Ferrer-i-Carbonell (2003) analyzed the "anatomy" of subjective well-being in different domains (job, environment, financial, housing, health and leisure), and a growing body of evidence underlines 
the importance of identifying specific and closer people in social networks related to social norm effects on proenvironmental behavior (Sevillano and Olivos, 2019). Moreover, we cannot answer which kind or component of happiness is elicited through our question. A more fine-grained understanding of resources of comparison will be achieved differentiating eudaimonic and hedonic kinds of happiness. For instance, to witness acquaintances' happiness based on momentary pleasure (hedonic) may have different effects than happiness due to personal growth or purposes in life (eudaimonic) ${ }^{6}$. In addition, the comparison process examined in this study is based on the happiness level of individuals and the reference group as a general subjective evaluation. We do not consider the life satisfaction of the reference group, which is a cognitive component of happiness (Diener, Lucas and Oishi, 2018; Raila et al., 2015). Thus, a possible extension of this research will be the understanding of social comparison processes within those particular components and kinds of happiness.

Finally, research using income reference groups has found a relation between the effect of the comparison on subjective well-being and mobility at the country level. Senik (2008) showed that in low mobility countries, there is a negative effect of upward comparison, which is positive in higher mobility countries. For our case, Torche (2005) found that Chile is as fluid as industrialized nations where equality is much higher. Furthermore, for cases like this, social mobility is a meaningful resource for comparison, as well as a cognitive process measured by people's perceptions. However, the Chilean case differs from the pattern of high mobility countries. Therefore, a discussion related to inequality instead of mobility should be addressed in this dynamically evolving field of research. Moreover, the intersection of Latin American collectivism (e.g. familismo) and fluid structural inequalities could explain the apparent paradox between collectivistic values and individualistic comparison in the case of Chile.

To conclude, despite myriad limitations and open-ended questions, we hope to have shown a deeper understanding of the relational values that shape life satisfaction in a Latin American country and the role of social networks in comparing with meaningful others. Happiness is certainly a psychological phenomenon, but it is intrinsic to human life and, as we have discussed, is influenced by social relationships.

\section{Ethical Statement}

All procedures performed in studies involving human participants were in accordance with the ethical standards of the institutional research committee and with the 1964 Helsinki declaration and its later

\footnotetext{
${ }^{6} \mathrm{We}$ thank one of the reviewers for pointing out the relevance of this distinction for our conclusions.
} 
amendments or comparable ethical standards. The corresponding author will share all data and codes for replication purpose upon request following an open science framework. The authors declare they have no conflict of interest.

\section{References}

Ateca-Amestoy V., Aguilar, A. \& Moro-Egido, A. (2014). Social Interactions and Life Satisfaction: Evidence from Latin America. Journal of Happiness Studies, 15(3), 527-554.

Back, K. (1951). Influence through social communication. Journal of Abnormal Psychology, 46(1), 9-23.

Baldwin, M., and Mussweiler, T. (2018). The culture of social comparison. PANAS, Proceedings of the National Academy of Sciences of the United States of America, 115(39), 9067-9074.

Bárcena-Martín, E., Cortés-Aguilar, A. \& Moro-Egido, A. (2017). Social Comparisons on Subjective WellBeing: The Role of Social and Cultural Capital. Journal of Happiness Studies, 18(4), 1121-1145.

Baumeister, R. \& Leary, M. (1995). The need to belong: desire for interpersonal attachments as a fundamental human motivation. Psychological Bulletin, 117(3), 497-529.

Beytía, P. (2016). The singularity of Latin American patterns of happiness. In M. Rojas (Ed.), Handbook of Happiness Research in Latin America. (pp. 17-29). New York: Springer.

Blanchflower, D. G., \& Oswald, A. J. (2008). Is well-being U-shaped over the life cycle?. Social Science \& Medicine, 66(8), 1733-1749.

Boissicat, N., Pansu, P., Bouffard, T. \& Cottin, F. (2012). Relation between perceived scholastic competence and social comparison mechanisms among elementary school children. Social Psychology of Education, $15(4), 603-614$.

Bruchmann, K. (2017). Compared to what? the importance of control groups in social comparison research. Basic and Applied Social Psychology, 39(2), 91-100.

Brüdel, J., Huyer-May, B., \& Schmiedeberg, C. (2013). Interviewer Behavior and the Quality of Social Network Data. In P.Winkler, R. Porst, \& N. Menold (Eds.), Interviewers' deviations in surveys: Impact, reasons, detection and prevention (pp. 147-160). Frankfurt: PeterLang. 
Bucher, A., Neubauer, A. B., Voss, A., \& Oetzbach, C. (2019). Together is better: Higher committed relationships increase life satisfaction and reduce loneliness. Journal of Happiness Studies, 20(8), 2445-2469.

Buunk, B., Collins, R., Taylor, S., Van Yperen, N. \& Dakof, G. (1990). The affective consequences of social comparison: either direction has its ups and downs. Journal of Personality and Social Psychology, 59(6), $1238-1249$.

Buunk, B. \& Van Ybema, J. (2003). Feeling bad, but satisfied: The effects of upward and downward comparison upon mood and marital satisfaction. British Journal of Social Psychology, 42(4), 613-628.

Campbell, D.E. (2009). Civic Engagement and Education: An Empirical Test of the Sorting Model. American Journal of Political Science, 53(4), 771-786.

Carrieri, V. (2012). Social Comparison and Subjective Well-Being: Does the Health of Others Matter?. Bulletin of Economic Research, 64(1), 31-55.

Cohen, A. B. (2002). The importance of spirituality in well-being for Jews and Christians. Journal of Happiness Studies, 3(3), 287-310.

Collins, R. (2000). Among the better ones: Upward assimilation in social comparison. In J. Suls \& L. Wheeler (Eds), Handbook of social comparison. (pp. 159-172). New York: Kluwer Academic/Plenum.

Contractor, N. \& DeChurch, L. (2014). Integrating social networks and human social motives to achieve social influence at scale. Proceedings of the National Academy of Sciences, 111(Supplement 4), 13650-13657.

Cook, K. \& Rice, E. (2006). Social Exchange Theory”. In J. DeLamater (Ed), Handbook of social psychology. (pp. 53-76). New York: Springer Science, Business Media.

Corcoran, K., Crusius, J. \& Mussweiler, T. (2011). Social Comparison: Motives, Standards and Mechanisms. In D. Chadee (Ed), Theories in social psychology. (pp. 119-139). Oxford, UK: Wiley-Blackwell.

Diener, E., Emmons, R., Larsen, R. \& Griffin, S. (1985). The satisfaction with life scale. Journal of Personality Assessment, 49(1), 71-75.

Diener, E. \& Fujita, F. (1997). Social comparisons and subjective well-being. In B. Buunk \& F. Gibbons (Eds), Health, coping and well-being: Perspectives from social comparison theory. (pp. 329-357). Mahwahm NJ: Lawrence Erlbaum Associates. 
Diener, E., Oishi, S., \& Tay, L. (2018). Advances in subjective well-being research. Nature Human Behaviour, 3, 253-260.

Diener, E., Lucas, R. E., \& Oishi, S. (2018). Advances and open questions in the science of subjective wellbeing. Collabra. Psychology, 4(1).

Diener, E., Suh, E., Smith, H. \& Shao, L. (1995). National differences in reported subjective well-being: Why do they occur?. Social Indicators Research, 34(1), 7-32.

Dirección de Estudios Sociales Universidad Católica. (2015). Tercer Barómetro de la Felicidad [Third Barometer of the Happiness, Data and code book]. Dataset.

Duesenberry, J. (1949). Income, saving and the theory of consumer behavior. Cambridge, Massachusetts: Harvard University Press.

Eagle, D. E., \& Proeschold-Bell, R. J. (2015). Methodological considerations in the use of name generators and interpreters. Social Networks, 40(Supplement C), 75-83.

Emerson, R. (1976). Social Exchange Theory. Annual Review of Sociology, 2(1), 335-362.

Esnaola, I., Benito, M., Antonio-Agirre, I., Ballina, E., \& Lorenzo, M. (2019). Gender, Age and Cross-Cultural Differences in Life Satisfaction: a Comparison Between Spain and Mexico. Child Indicators Research, 12(6), 1935-1949.

Falicov, C. J. (2000). Latino families in therapy: A guide to multicultural practice. New York: Guilford Press.

Feiereisen, S., Broderick, A. J., \& Douglas, S. P. (2009). The effect and moderation of gender identity congruity: Utilizing “real women” advertising images. Psychology \& Marketing, 26(9), 813-843.

Ferrer-i-Carbonell, A. (2005). Income and well-being: an empirical analysis of the comparison income effect. Journal of Public Economics, 89(5-6), 997-1019.

Festinger, L. (1954). A Theory of Social Comparison Processes. Human Relations, 7(2), 117-140.

Firebaugh, G., \& Schroeder, M. B. (2009). Does your neighbor's income affect your happiness?. American Journal of Sociology, 115(3), 805-831.

Fisher, J. (1988). Possible effects of reference group-based social influence on AIDS-risk behavior and AIDSprevention. American Psychologist, 43(11), 914-920.

Fiske, S. (2010). Envy Up, Scorn Down: How Comparison Divides Us. The American Psychologist 65(8), 698706. 
Frieswijk, N., Buunk, B., Steverink, N. \& Slaets, J. (2004), The effect of social comparison information on the life satisfaction of frail older persons. Psychology and Aging, 19(1), 183-190.

Frison, E. \& Eggermont, S. (2016). 'Harder, Better, Faster, Stronger': Negative Comparison on Facebook and Adolescents' Life Satisfaction Are Reciprocally Related. CyberPsychology, Behavior and Social Networking, 19(3), 158-164.

Gächter, S., Nosenzo, D., \& Sefton, M. (2012). The Impact of Social Comparisons on Reciprocity. The Scandinavian Journal of Economics, 114(4), 1346-1367.

Gächter, S., \& Thöni, C. (2010). Social comparison and performance: Experimental evidence on the fair wageeffort hypothesis. Journal of Economic Behavior \& Organization, 76(3), 531-543.

Gilbert, D. T., Giesler, R. B., \& Morris, K. A. (1995). When comparisons arise. Journal of personality and social psychology, 69(2), 227.

Göetz, T., Ehret, C., Jullien, S., \& Hall, N. C. (2006). Is the grass always greener on the other side? Social comparisons of subjective well-being. The Journal of Positive Psychology, 1(4), 173-186.

Granovetter, M, (1973), The Strength of Weak Ties. American Journal of Sociology, 78(6), 1360-1380.

Guillen-Royo, M. (2008). Consumption and Subjective Wellbeing: Exploring Basic Needs, Social Comparison, Social Integration and Hedonism in Peru. Social Indicators Research, 89(3), 535-555.

Hatfield, E., Cacioppo, J. \& Rapson, R. (1994). Emotional contagion: Cambridge studies in emotion and social interaction. Cambridge, UK: Cambridge University Press.

Helliwell, J., Layard, R. \& Sachs, J. (2017). World Happiness Report 2017. New York: Sustainable Development Solutions Network.

Hofstede, G. (1980). Culture's Consequences: International Differences in Work-Related Values (Abridged edition). Beverly Hills: SAGE Publications, Inc.

Huang, X., Western, M., Bian, Y., Li, Y., Côté, R., \& Huang, Y. (2019). Social networks and subjective wellbeing in Australia: New evidence from a national survey. Sociology, 53(2), 401-421.

Jasso, G. (1990). Methods for the Theoretical and Empirical Analysis of Comparison Processes. Sociological Methodology, 20, 369-419.

Josten, M., \& Trappmann, M. (2016). Interviewer Effects on a Network-Size Filter Question. Journal of Official Statistics, 32(2), 349-373. 
Marsden, P. \& Friedkin, N. (1993). Network Studies of Social Influence. Sociological Methods \& Research, 22(1), 127-151.

Marsden, P. V. (2003). Interviewer effects in measuring network size using a single name generator. Social Networks, 25(1), 1-16.

Marsh, H. W., \& Hau, K. (2003). Big-fish-little-pond effect on academic self-concept: A cross-cultural (26country) test of the negative effects of academically selective schools. American Psychologist, 58, 364376.

McBride, M. (2001). Relative-income effects on subjective well-being in the cross-section. Journal of Economic Behavior \& Organization, 45, 251-278.

Miller, P., Bobkowski, P., Maliniak, D. \& Rapoport, R. (2015). Talking Politics on Facebook: Network Centrality and Political Discussion Practices in Social Media. Political Research Quarterly, 68(2), 377391.

Morry, M. (2005), Relationship satisfaction as a predictor of similarity ratings: A test of the attraction similarity hypothesis. Journal of Social and Personal Relationships, 22(4), 561-584.

Moyano-Díaz, E. (2010). Calidad de vida y psicología en el bicentenario de Chile. Chile: Universidad de Talca.

Moyano-Díaz, E. (2016). Trends and Challenges for the Research of Happiness in Latin America. In M. Rojas (Ed.), Handbook of happiness research in Latin America (pp. 63-87). Dordrecht, Netherlands: Springer.

Mussweiler, T. (2003). Comparison processes in social judgment: Mechanisms and consequences. Psychological Review, 110(3), 472-489.

Mussweiler, T., Rüter, K., \& Epstude, K. (2004). The ups and downs of social comparison: mechanisms of assimilation and contrast. Journal of Personality and Social Psychology, 87(6), 832.

Nie, N.H., Junn, J., \& Stehlik-Barry, K. (1996). Education and democratic citizenship in America. Chicago: The University of Chicago Press.

Park, J., Joshanloo, M., \& Scheifinger, H. (2019). Predictors of life satisfaction in a large nationally representative Japanese sample. Social Science Research, 82, 45-58.

Paul, K. I., \& Moser, K. (2009). Unemployment impairs mental health: Meta-analyses. Journal of Vocational Behavior, 74(3), 264-282. 
Pavot, W., \& Diener, E. (1993). The affective and cognitive context of self-reported measures of subjective well-being. Social Indicators Research, 28(1), 1-20.

Pavot, W., \& Diener, E. (2008). The Satisfaction With Life Scale and the emerging construct of life satisfaction. The Journal of Positive Psychology, 3(2), 137-152.

Poelker, K. E., Gibbons, J. L., \& Maxwell, C. A. (2019). The relation of perspective-taking to gratitude and envy among Guatemalan adolescents. International Perspectives in Psychology: Research, Practice, Consultation, 8(1), 20.

Raila, H., Scholl, B. J., \& Gruber, J. (2015). Seeing the world through rose-colored glasses: People who are happy and satisfied with life preferentially attend to positive stimuli. Emotion, 15(4), 449.

Rodríguez-Pose, A., \& Von Berlepsch, V. (2014). Social capital and individual happiness in Europe. Journal of Happiness Studies, 15(2), 357-386.

Rojas. M. (2016). The Relevance of Happiness: Choosing Between Development Paths in Latin America. In M. Rojas (Ed), Handbook of happiness research in Latin America. (pp. 51-62). New York: Springer.

Rojas, M., Martínez, I., Calvo, E., Millán, R., Moyano, E., Palomar, J., . . Y Yamamoto, J. (2012). Medición, investigación e incorporación a la política pública del bienestar subjetivo: América Latina. México: Foro Consultivo Científico y Tecnológico.

Rosenbaum, P. \& Rubin, D. (1983). The central role of the propensity score in observational studies for causal effects. Biometrika, 70(1), 41-55.

Schlosser, A. \& Levy, E. (2016). Helping others or oneself: How direction of comparison affects prosocial behavior. Journal of Consumer Psychology, 4(26), 461-473.

Senik, C. (2008). Ambition and Jealousy: Income Interactions in the 'Old' Europe versus the 'New' Europe and the United States. Economica, 75(299), 495-513.

Sevillano, V., and Olivos, P. (2019) Comportamiento social y ambiente: influencia de las normas sociales en la conducta ambiental. Papeles del Psicólogo. Advance online publication.

Singer, J. (1980). Social comparison: The process of self-evaluation. New York: Oxford University Press.

Steele, L. G., \& Lynch, S. M. (2013). The pursuit of happiness in China: Individualism, collectivism, and subjective well-being during China's economic and social transformation. Social Indicators Research, 114(2), 441-451. 
Suh, E., Diener, E. \& Oishi, S. (1998). The shifting basis of life satisfaction judgments across cultures: emotions versus norms. Journal of Personality and Social Psychology, 74(2), 482-493.

Tajfel, H. (1982). Social Psychology of Intergroup Relations. Annual Review of Psychology, 33(1), 1-39.

Taylor, S. \& Lobel, M. (1989). Social comparison activity under threat: downward evaluation and upward contacts. Psychological Review, 96(4), 569-575.

Taylor, S., Wayment, H. \& Carrillo, M. (1996). Social comparison, self-regulation and motivation. In R. Sorrentino \& E. Higgins (Eds), Handbook of motivation and cognition. (pp. 3-27). New York: Guilford Press.

The World Bank. (2017). World Development Indicators [Data File].

Torche, F. (2005). Unequal But Fluid: Social Mobility in Chile in Comparative Perspective. American Sociological Review, 70(3), 422-450.

Triandis, H., \& Gelfand, M. (2011). A theory of individualism and collectivism. In P. A. V. Lange, A. W. Kruglanski, \& E. T. Higgins (Eds.), Handbook of theories of social psychology (1st ed., Vol. 2, pp. 498520). Thousand Oaks: Sage.

United Nations Development Programme. (2012). Bienestar Subjetivo: El Desafíos De Repensar El Desarrollo. Santiago, Chile: PNUD.

Valente, R. R., \& Berry, B. J. (2016). Working hours and life satisfaction: A cross-cultural comparison of Latin America and the United States. Journal of Happiness Studies, 17(3), 1173-1204.

Van Praag, B.M.S., Frijters, P., \& Ferrer-i-Carbonell, A. (2003). The anatomy of subjective well-being. Journal of Economic Behavior \& Organization, 51, 29-49

Vera-Villarroel, P., Urzúa, M. A., Pavez, P., Celis-Atenas, K. \& Silva, J. (2012). Evaluation of Subjective Wellbeing: Analysis of the Satisfaction With Life Scale in Chilean Population. Universitas Psychologica, 11 (3), 719-727.

Welsch, H., \& Kühling, J. (2015). Income comparison, income formation, and subjective well-being: New evidence on envy versus signaling. Journal of Behavioral and Experimental Economics, 59, 21-31.

Wills, T. (1981). Downward comparison principles in social psychology. Psychological Bulletin, 90(2), 245271. 
Wood, J. V. (1996). What is social comparison and how should we study it?. Personality and Social Psychology Bulletin, 22(5), 520-537.

Yang, Y. (2008). Social inequalities in happiness in the United States, 1972 to 2004: An age-period-cohort analysis. American Sociological Review, 73(2), 204-226.

Young, A., Gabriel, S. \& Schlager, O. (2014). Does this friend make me look fat? appearance-related comparisons within women's close friendships. Basic and Applied Social Psychology, 36(2), 145-154.

Zell, E., \& Alicke, M.D. (2010). The local dominance effect in self-evaluation: Evidence and explanations. Personality and Social Psychology Review. 14, 368-384. 


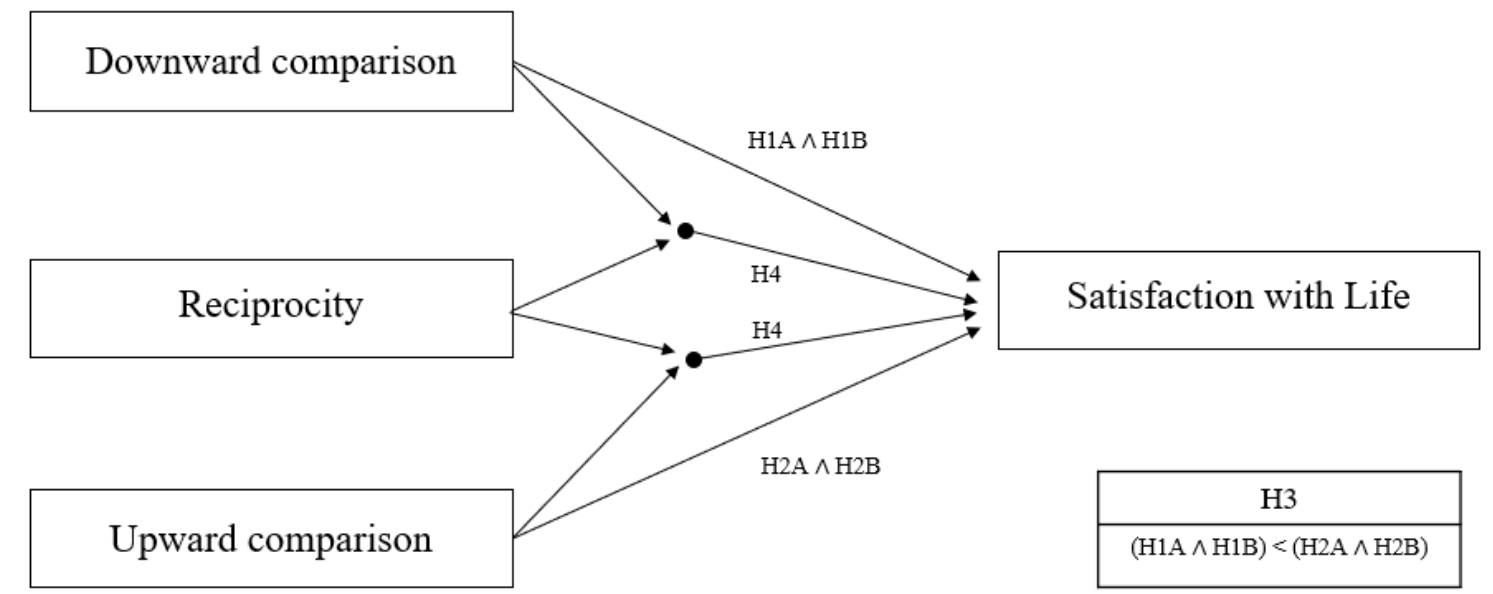

Note: The path from reciprocity to SWL is included in the empirical models, but it is not part of the hypotheses.

Figure 1. Theoretical Model 
Table 1

Descriptive statistics

\begin{tabular}{|c|c|c|c|c|c|c|c|}
\hline Ego variables & & Mean & $\%$ & $S D$ & Min & Max & $N$ \\
\hline SWLS & & 23.97 & & 6.45 & 5 & 35 & 1,596 \\
\hline Age & & 44.73 & & 17.37 & 18 & 95 & 1,596 \\
\hline SP of health & & 3.71 & & 0.87 & 1 & 5 & 1,596 \\
\hline Educational lev & evel & & & & & & 1,596 \\
\hline & Higher education & & 43.39 & & & & \\
\hline \multicolumn{8}{|l|}{ Gender } \\
\hline & Male & & 35.46 & & & & 1,596 \\
\hline Labor market st & status & & & & & & 1,596 \\
\hline & Employed & & 54.14 & & & & \\
\hline & Unemployed & & 3.95 & & & & \\
\hline & Inactive & & 41.92 & & & & \\
\hline Marital status & & & & & & & 1,596 \\
\hline & Single & & 42.36 & & & & \\
\hline & Married & & 41.42 & & & & \\
\hline & Others & & 16.23 & & & & \\
\hline \multicolumn{8}{|l|}{ Alters variables } \\
\hline Network size & & 2.32 & & 1.32 & 1 & 5 & 1,596 \\
\hline Age & & 43.5 & & 14.6 & 5 & 93 & 1,596 \\
\hline Higher educatic & & 0.40 & & 0.44 & 0 & 1 & 1,596 \\
\hline Male & & 0.40 & & 0.38 & 0 & 1 & 1,596 \\
\hline Family kinship & & 0.48 & & 0.43 & 0 & 1 & 1,596 \\
\hline \multicolumn{8}{|l|}{ Network variables } \\
\hline Down & & 0.22 & & 0.45 & 0 & 3 & 1,596 \\
\hline Up & & 0.43 & & 0.61 & 0 & 3 & 1,596 \\
\hline Reciprocity & & & & & & & 1,596 \\
\hline & Yes & & 83.77 & & & & \\
\hline Date of survey & & & & & & & 1,596 \\
\hline & Nov 1st - Dec 15th & & 37.53 & & & & \\
\hline & Dec 16th - Jan 1st & & 6.83 & & & & \\
\hline & Jan 2nd - 30th & & 55.64 & & & & \\
\hline
\end{tabular}

Note: Descriptive statistics are estimated based on restricted sample. 
Table 2

Summary of OLS regressions analysis for variables predicting life satisfaction

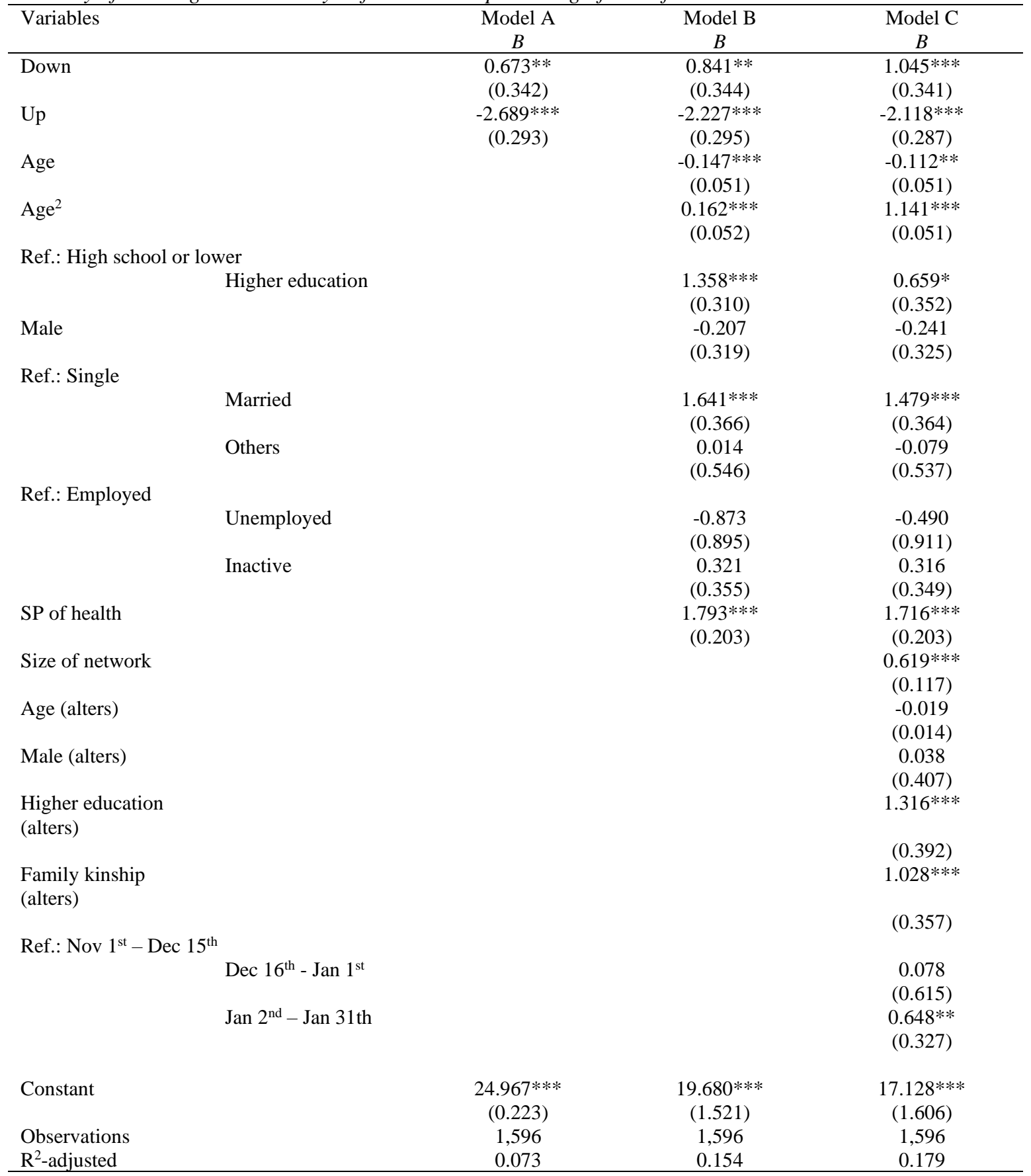

Note: Robust standard errors in parentheses; $* * * p<0.01, * * p<0.05, * p<0.1$. 
Table 3

Summary of OLS regressions analysis including interactions

\begin{tabular}{lcccc}
\hline Variables & Model D & Model E & Model F & Model G \\
& $B$ & $B$ & $B$ & $B$ \\
\hline Down & $1.113^{* * *}$ & $2.392^{* * *}$ & $1.111^{* * * *}$ & $2.570^{* * *}$ \\
& $(0.340)$ & $(0.805)$ & $(0.340)$ & $(0.858)$ \\
Up & $-2.136^{* * *}$ & $-2.132^{* * *}$ & $-2.220^{* * *}$ & $-1.762^{* * *}$ \\
& $(0.285)$ & $(0.286)$ & $(0.636)$ & $(0.670)$ \\
Reciprocity & $2.368^{* * *}$ & $2.763 * * *$ & $2.328^{* * *}$ & $2.991 * * *$ \\
& $(0.411)$ & $(0.479)$ & $(0.475)$ & $(0.596)$ \\
Reciprocity\#Down & & $-1.554 *$ & & $-1.760^{*}$ \\
& & $(0.865)$ & & $(0.932)$ \\
Reciprocity\#Up & & & 0.098 & -0.433 \\
& & & $(0.683)$ & $(0.730)$ \\
Constant & $14.992^{* * *}$ & $14.598 * * *$ & $15.029 * * *$ & $14.380^{* * *}$ \\
& $(1.591)$ & $(1.620)$ & $(1.609)$ & $(1.667)$ \\
Observations & 1,596 & 1,596 & 1,596 & 1,596 \\
$\mathrm{R}^{2}$-adjusted & 0.196 & 0.198 & 0.196 & 0.197 \\
\hline
\end{tabular}

Note: Robust standard errors in parentheses; $* * * p<0.01, * * p<0.05, * p<0.1$. Controls are not reported. 


\section{Supplementary material I}

Table S1

Descriptive statistics before listwise deletion

\begin{tabular}{|c|c|c|c|c|c|c|c|}
\hline Ego variables & & Mean & $\%$ & $S D$ & Min & Max & $N$ \\
\hline SWLS & & 24.11 & & 6.62 & 5 & 35 & 2075 \\
\hline Age & & 44.70 & & 17.09 & 18 & 95 & 2,127 \\
\hline SP of health & & 3.72 & & 0.88 & 1 & 5 & 2,111 \\
\hline Educational lev & & & & & & & 2,127 \\
\hline & Higher education & & 40.34 & & & & \\
\hline Gender & & & & & & & 2,127 \\
\hline & Male & & 36.30 & & & & \\
\hline Labor market st & status & & & & & & 2,108 \\
\hline & Employed & & 55.98 & & & & \\
\hline & Unemployed & & 3.84 & & & & \\
\hline & Inactive & & 40.18 & & & & \\
\hline Marital status & & & & & & & 2,108 \\
\hline & Single & & 42.03 & & & & \\
\hline & Married & & 42.31 & & & & \\
\hline & Others & & 15.65 & & & & \\
\hline \multicolumn{8}{|l|}{ Alters variables } \\
\hline Network size & & 2.34 & & & 1 & 5 & 2,127 \\
\hline Age & & 43.62 & & 14.54 & 5 & 93 & 2,034 \\
\hline Higher educatic & & 0.41 & & 0.44 & 0 & 1 & 1,929 \\
\hline Male & & 0.41 & & 0.39 & 0 & 1 & 2,121 \\
\hline Family kinship & & 0.45 & & 0.44 & 0 & 1 & 2,127 \\
\hline \multicolumn{8}{|l|}{ Network variables } \\
\hline Down & & 0.20 & & 0.43 & 0 & 3 & 2,114 \\
\hline Up & & 0.42 & & 0.61 & 0 & 3 & 2,106 \\
\hline \multirow{2}{*}{\multicolumn{2}{|c|}{ Reciprocity }} & & & & & & 2,117 \\
\hline & & & 81.06 & & & & \\
\hline Date of survey & & & & & & & 1,924 \\
\hline & Nov 1st - Dec 15th & & 38.59 & & & & \\
\hline & Dec 16th - Jan 1st & & 6.41 & & & & \\
\hline & Jan 2nd - 30th & & 55.00 & & & & \\
\hline
\end{tabular}

Note: Descriptive statistics are estimated based on restricted sample. 


\section{Supplementary material II}

Table S2

Wording and distribution for SWLS items

\begin{tabular}{|c|c|c|c|c|c|c|c|c|}
\hline Variable & $\begin{array}{l}\text { Completely } \\
\text { disagree }\end{array}$ & 2 & 3 & 4 & 5 & 6 & $\begin{array}{l}\text { Completely } \\
\text { agree }\end{array}$ & Mean \\
\hline $\begin{array}{l}\text { In most ways my life is close } \\
\text { to my ideal }\end{array}$ & 2.26 & 7.77 & 11.47 & 13.16 & 27.63 & 29.07 & 8.65 & 4.78 \\
\hline $\begin{array}{l}\text { The conditions of my life are } \\
\text { excellent }\end{array}$ & 1.82 & 9.09 & 12.22 & 20.36 & 27.32 & 22.31 & 6.89 & 4.57 \\
\hline I am satisfied with my life & 1.63 & 8.27 & 9.27 & 15.48 & 22.87 & 30.20 & 12.28 & 4.89 \\
\hline $\begin{array}{l}\text { So far, I have achieved the } \\
\text { important things I want in life }\end{array}$ & 1.38 & 5.14 & 8.52 & 15.79 & 24.87 & 29.39 & 14.91 & 5.05 \\
\hline $\begin{array}{l}\text { If I could live my life over, I } \\
\text { would change almost nothing }\end{array}$ & 5.58 & 9.02 & 13.22 & 14.04 & 18.30 & 22.81 & 17.04 & 4.67 \\
\hline
\end{tabular}


Table S3

Correlations between independent variables and controls

\begin{tabular}{|c|c|c|c|c|c|c|c|c|c|c|c|c|c|c|c|c|}
\hline & Down & Up & Recip. & $\begin{array}{l}\text { Net. } \\
\text { size }\end{array}$ & Age & Age2 & Educ. & Gender & $\begin{array}{l}\text { Marital } \\
\text { status }\end{array}$ & $\begin{array}{l}\text { Labor } \\
\text { status }\end{array}$ & $\begin{array}{l}\text { SP of } \\
\text { Health }\end{array}$ & Date & $\begin{array}{l}\text { Age } \\
\text { alters }\end{array}$ & $\begin{array}{l}\text { Gender } \\
\text { alters }\end{array}$ & $\begin{array}{l}\text { Educ. } \\
\text { alters }\end{array}$ & $\begin{array}{l}\text { Family } \\
\text { kinship }\end{array}$ \\
\hline Down & 1 & & & & & & & & & & & & & & & \\
\hline Up & -.337 & 1 & & & & & & & & & & & & & & \\
\hline Recip. & -.067 & .027 & 1 & & & & & & & & & & & & & \\
\hline Net. size & -.006 & -.132 & -.155 & 1 & & & & & & & & & & & & \\
\hline Age & -.067 & .211 & -.090 & -.162 & 1 & & & & & & & & & & & \\
\hline Age2 & -.067 & .207 & -.079 & -.158 & .982 & 1 & & & & & & & & & & \\
\hline Educ. & -.096 & -.094 & .066 & .168 & -.318 & -.338 & 1 & & & & & & & & & \\
\hline Gender & -.034 & -.029 & -.001 & .020 & -.020 & -.011 & .106 & 1 & & & & & & & & \\
\hline Marital status & -.061 & .140 & -.009 & -.103 & .603 & .563 & -.236 & -.111 & 1 & & & & & & & \\
\hline Labor status & -.055 & .093 & .022 & -.071 & .292 & .370 & -.301 & -.429 & .224 & 1 & & & & & & \\
\hline SP of Health & .062 & -.170 & .065 & .145 & -.393 & -.380 & .276 & .115 & -.260 & -.258 & 1 & & & & & \\
\hline Date & .009 & -.002 & .135 & -.108 & -.010 & -.010 & .096 & .052 & -.023 & -.005 & -.023 & 1 & & & & \\
\hline Age alters & -.003 & .096 & -.057 & -.103 & .643 & .615 & -.156 & -.005 & .343 & .160 & -.290 & .005 & 1 & & & \\
\hline Gender alters & -.048 & -.001 & .013 & .082 & -.051 & -.060 & .055 & .378 & -.041 & -.137 & .097 & -.024 & -.047 & 1 & & \\
\hline Educ. alters & -.096 & -.033 & .127 & .120 & -.147 & -.153 & .619 & .028 & -.070 & -.145 & .183 & .104 & -.190 & .113 & 1 & \\
\hline Family kinship & -.041 & .048 & .158 & -.093 & .118 & .125 & -.177 & .047 & .054 & .078 & -.103 & .055 & .103 & .033 & -.114 & 1 \\
\hline
\end{tabular}




\section{Supplementary material III}

We ran two PSMs separately, and we then compared the average treatment effect of both. In the first, the treatment was defined as the downward comparison. The downward comparison variable was transformed into a dummy variable where 0 means targets that are happier than or equally as happy as ego, and 1 means targets less happy than ego. Therefore, the treatment is a downward comparison. The second PSM considers the treatment as any upward comparison. In order to create groups with similar characteristics, we defined the independent and control variables used in the previous models as covariates. Table S4 shows the balance of these key variables in the raw data and the weighted data after matching. There are initial differences which were balanced through the matching. Figure S1 reports balance plots for both PSMs. Covariates are balanced in an experimental design because treatment condition is independent of those covariates. However, with PSM, the distribution of covariates across groups is equalized ex-post. PSM assumes there are no unobserved confounders. Raw density graphs indicate that respondents of treatment and control groups have different probabilities to be assigned to the treatment given the aforementioned covariates. Nevertheless, after matching, there is no difference. This approach shares the limitations of any study based on observational data. For instance, some relevant covariates could have been omitted. However, this analysis is a step forward in social comparison research and provides robustness to our estimations.

Table S4

Standardized difference in means

\begin{tabular}{lcccc}
\hline \multicolumn{1}{c}{ Variables } & \multicolumn{2}{c}{ Downward comparison } & \multicolumn{2}{c}{ Upward comparison } \\
& Matched & Raw & Matched & Raw \\
\hline Age & -0.197 & 0.032 & 0.361 & -0.009 \\
SP of health & 0.176 & 0.026 & -0.253 & 0 \\
Educational level & -0.074 & 0.050 & -0.056 & 0 \\
Gender & -0.081 & 0.064 & -0.029 & -0.019 \\
Labor market status & -0.088 & -0.011 & 0.097 & -0.030 \\
Marital status & -0.145 & 0.062 & 0.220 & 0.002 \\
Size of network & 0.270 & -0.039 & -0.003 & -0.001 \\
Age of alters & 0.005 & 0.061 & 0.194 & 0.016 \\
Higher education of alters & -0.140 & -0.024 & 0.015 & 0.018 \\
Gender of alters & -0.082 & -0.027 & 0.021 & 0.070 \\
Family kinship & -0.073 & -0.02 & 0.014 & 0.010 \\
Reciprocity & -0.143 & 0.013 & -0.024 & -0.068 \\
Date of survey & 0.05 & 0.106 & -0.015 & 0.007 \\
\hline
\end{tabular}




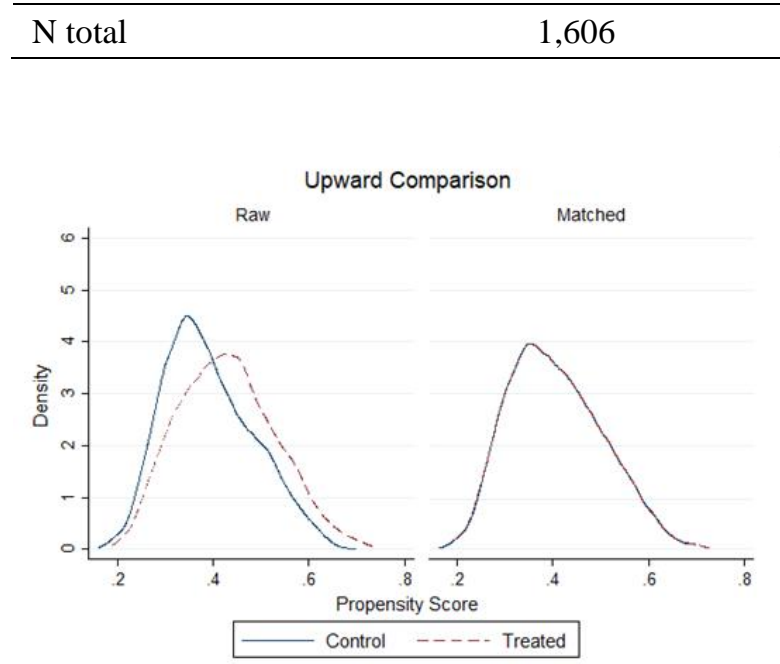

Figure S1. Density of propensity scores for raw and weighted data after matching

Table S5 suggests that both treatments (downward and upward comparison) have significant effects on life satisfaction. Downward comparison increases life satisfaction $(B=2.260, p<.01)$. Likewise, upward comparison decreases a person's satisfaction with life $(B=-3.380, p<.01)$.

Table S5

Average treatment effect on the treated

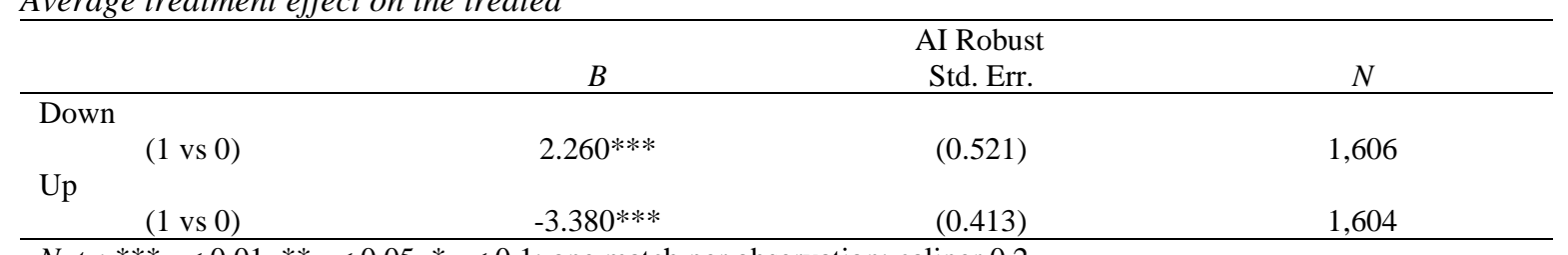

Note: ${ }^{* * *} p<0.01, * * p<0.05, * p<0.1$; one match per observation; caliper 0.2 . 